\title{
A Cooperative and Dialogic Development Increases Well-being at Work
}

\author{
By Hannele Laaksonen* \\ Pirkko Kivinen ${ }^{\dagger}$ \\ Lasse Lehmuskoskit
}

\begin{abstract}
The national development project "Productivity and Competitive Strength through Joy of Working (2016-2017)" was funded by European Social Fund and implemented in three Finnish regions: Tampere region, Northern Savonia and South Ostrobothnia. The project was conducted by Tampere University Work Research Centre, Tampere University of Applied Sciences, Savonia University of Applied Sciences and Seinäjoki University of Applied Sciences. The project was cooperative, dialogic and research-assisted in nature and its goal was to increase productivity, well-being at work, cost-efficiency and competitiveness in participating companies $(N=11)$. This article focuses on the results of two care companies that took part in the project. The research question is: What kind of effect did the project have on employees' well-being? The data were gathered through an electronic questionnaire that was filled out by the personnel at the beginning and at the end of the project. The response rate was $65 \%(n=65)$ at the initial measurement and $54 \%$ $(n=54)$ at the final measurement. The questionnaire consisted of more than 150 statements of which 62 measuring well-being at work were selected for this study. The data were statistically analyzed using SPSS. There was a statistically significant change in employees' well-being between the initial and final measurements. Respondents in the final measurement estimated that the project had positively affected communication (55\%), performing the basic tasks (53\%), well-being at work (52\%), development at the workplace (50\%), interpersonal relationships and atmosphere (49\%) and relationship between employees and employers (49\%). Employees' joy of working was strongly correlated with versatility and clear distribution of work whereas lack of opportunities to affect the working pace and the prevalence of gossiping within the work community were associated with employees' increased mental workload.
\end{abstract}

Keywords: cooperative development, dialogic development, joy of work, well-being.

\section{Introduction}

Finland experienced a deep economic depression between 1990 and 1993, which caused personnel reductions and demands for more efficiency in all fields. The burden on the remaining personnel increased, resulting in a significant decrease in experiencing work as meaningful and joyful. There was a temporary turn towards the better between 1994 and 2000, but experiences have fallen again since 2001, being particularly low in 2004 and 2012. Results in 2016 suggest the

\footnotetext{
*Post-doc Researcher Principal Lecturer, Tampere University of Applied Sciences, Finland. ${ }^{\dagger}$ Post-doc Researcher Principal Lecturer, Tampere University of Applied Sciences, Finland.

${ }^{\star}$ Master of Health Care, RN, Pirkanmaa Hospital District / Tampere University Hospital, Finland.
} 
trend may be turning (Figure 1) (Mähönen 2017).

Figure 1. Balance of Trends in Experiencing Work as Meaningful and Joyful 1992-2016 (Percentage Points)

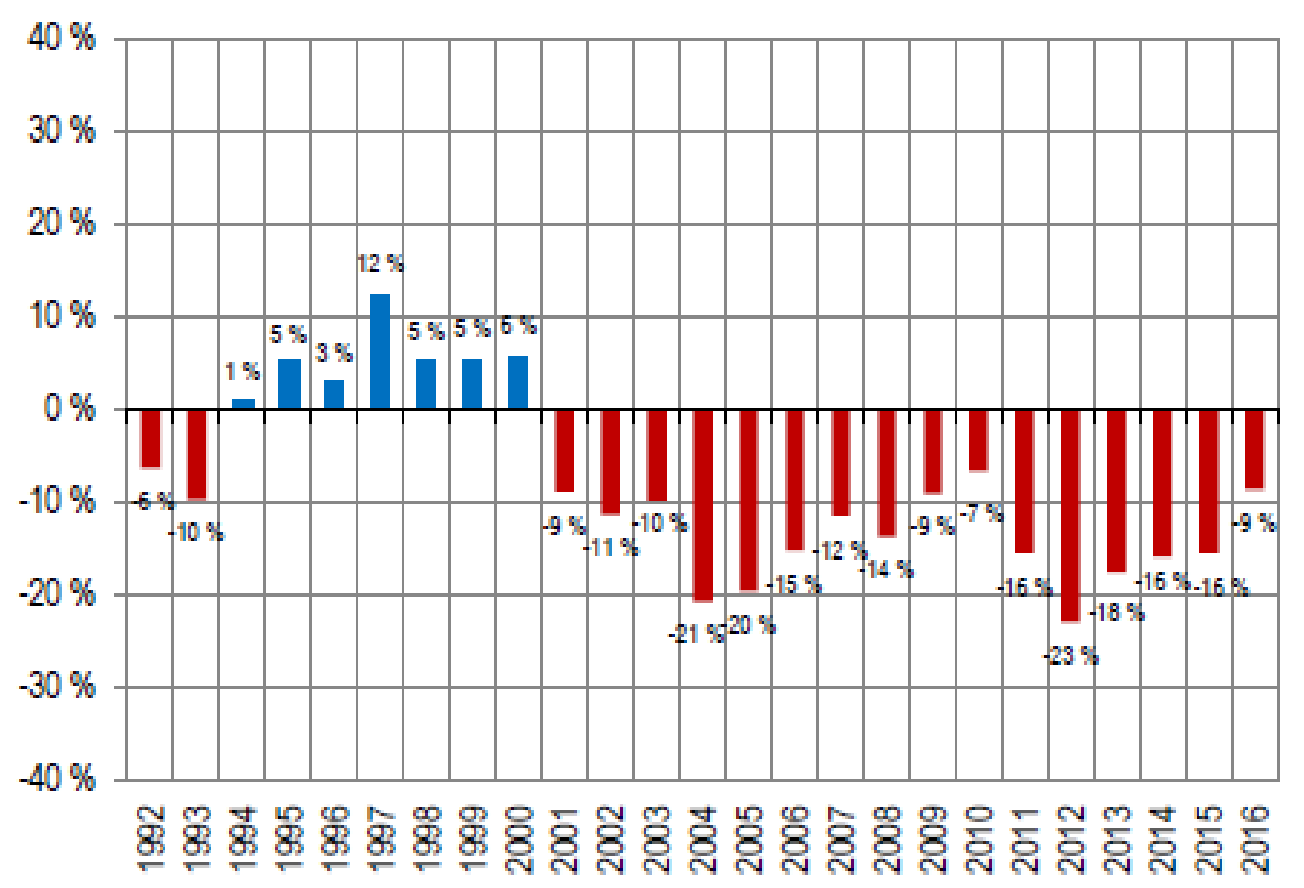

Source: Mähönen 2017.

Studying employee well-being is extremely important, as only happy and contented employees use their full potential, are productive and provide quality health care. Employee well-being can be seen as a whole formed by a sense of meaning, health and safety (Mähönen 2017, Celma et al. 2018). Manka et al. (2011: 8) broaden employee well-being to consist of four areas: organization factors, manager factors, group factors and work factors. Organization factors include goals, flexible structures, constant development and functioning work environments. Managers who lead by encouraging and empowering employees increase their employees' well-being. Important group factors include team spirit, openness, functionality and common rules. Significant work factors are opportunities to affect things, learning and rewards. As employee well-being is a broad and multifaceted concept, job satisfaction is easier to limit to mean the employee's positive thinking and attitude towards the work and work environment (Robbins and Judge 2012: 74-75). Joy through work rises from the employee's experiences of success, being allowed to use their expertise, and receiving support and feedback (Manka et al. 2011: 8).

Opportunities for promotion, education and professional challenges increase employee satisfaction (Lorber and Savic 2012). The ability to control one's work and opportunities to advance in one's career increase commitment, while tasks that require little skill are predictors for changing jobs (Sawatzky et al. 2015, Sveinsdóttir and Blöndal 2014).

One preprequisite for employee well-being is the employee's trust in their 
manager. Lack of trust in the manager decreases employee loyalty and work motivation (Seifert et al. 2016). The possibility of specializing in a specific area of work increases workplace commitment (Sloan et al. 2017). Giving employees more opportunities to affect their work can be used to improve their attitudes, well-being and work efficiency (Ogbonnaya and Valizade 2015).

In their broad study of nurses, Brunetto et al. (2013) found that the managernurse relationship, co-operation and employee well-being accounted for nearly half of nurses' commitment to the hospital, or alternatively their plans to leave. They also discovered that baby boomer nurses experienced greater well-being and commitment than younger nurses. Jones's study (2015) however discovered no difference in commitment between nurses of different ages, but found that practical nurses had statistically significantly lower levels of commitment to the workplace than registered nurses.

Professional commitment, work environment and workplace values have been found to be connected to employee well-being (Caricati et al. 2014). Experiences of trust and a fair and attractive system of rewards also have a significant effect on employee satisfaction and commitment to the organization (Hsu et al. 2015). Fairness in leadership and particularly fairness in procedures has been found to increase older nurses' remaining at workplaces. Older and younger nurses may have different needs, which managers should recognize to be able to meet the needs of all their subordinates (Armstrong-Stassen et al. 2015).

Positive humour between managers and employees increases employees' commitment to their work (Goswami et al. 2016). Joy of working is connected to commitment to the workplace and work goals (Plester and Hutchison 2016) as well as being absorbed in the work and patient-centric care (Abdelhadi and DrachZahavy 2012). Workplaces can increase job satisfaction by the most effective practices, which are job security (permanent contracts), working in teams and nondiscrimination. To increase trust in management, the most effective practices are non-discrimination, motherhood not hurting the employee's career, full-time work, and internal information on the firm's goals (Celma et al. 2018). Research findings have shown that investing in employee well-being is economically viable for every organization, as it has a positive relationship to productivity, customer satisfaction and employee sustainability.

This article presents the results of a national project of employee well-being and productivity. The national development project "Productivity and Competitive Strength through Joy of Working (2016-2017)" was funded by the European Social Fund and implemented in three Finnish regions: Tampere, Northern Savonia and Southern Ostrobothnia. The project was conducted by Tampere University Work Research Centre, Tampere University of Applied Sciences, Savonia University of Applied Sciences and Seinäjoki University of Applied Sciences. The project was cooperative, dialogic and research-assisted in nature. Its goal was to increase productivity, well-being at work, cost-efficiency and competitiveness in participating companies $(\mathrm{N}=11)$. 


\section{The Organization as a System}

Community and communality are concepts related to whether humans feel a sense of togetherness, and what unites people in communities. Communities can be spatial, such as continents, cities or villages, or formal such as universities and companies. People within the same structure do not however necessarily feel a clear sense of togetherness. Large communal unions or corporate fusions can cause a feeling of separateness, and the formation of a new sense of community can take years or ever decades (Nivala 2008). To enable the members of work communities to function together and in accordance with common goals, the organizational leadership must understand the phenomena of community dynamics and culture.

Organizational culture can be analyzed as a factor influencing the organizationnal system (Roman 2017). From a system theoretic approach, organizations are social units which consist of sub-systems and which are built and re-built to reach specific goals. How the organization functions is formed by the interrelationships between sub-systems and the system and its environment.

According to Roman (2017), a systemic understanding means that nothing and no one exists in a vacuum and that everything affects everything. For instance, a work community forms a system, which itself is part of another system, such as an organization or the entire field. The functioning of a work community is thus born from interactions, only a small part of which are visible. This is also related to the workplace culture, which makes the members of the group act and even feel in certain ways. A group's culture is born through its history, which is why situations such as heavy reductions of personnel, threats of bankruptcy or removals of leaders influence communities even after the situation is over. Uniting organizations and large mergers cause resistance to change, which can rise from the personnel's loyalty to the old leaders or workplace culture (Roman 2017).

The formation of community in a work organization is however subservient to its hierarchical nature. The leadership determines the goals of the organization and hires the staff to reach them. Despite this, there is nearly always an unofficial organization under the official organizational structure, whose functioning can be unreachable to the leadership (Kuittinen and Kejonen 2009).

\section{Structures of Cooperation}

Structures of cooperative development require procedures that allows for interaction in the workplace. If the culture of leadership at the workplace has traditionally been authoritarian or heavily instructive, adopting new practices may require educating both the leadership and personnel. Meeting practices, work culture within teams, physical work environments and the availability of managers are precisely the so called structures, which can either enable employees to influence their work environment and feel part of the community or deny them the opportunity.

In his book, Ari Rämö (2015) considers why it is sometimes difficult for leaders or managers to give a voice and influence to their subordinates. Some key 
questions are whether the superior feels that by giving another power they are losing part of their role as superior for which they have worked, and whether there is a learned habit of the superior making the decisions in the organization. Having employees participate in planning and decision-making requires an organization with a clear and understood way of working, which is based on cooperatively formed goals and strategy. Trust is based on appreciating the employee and believing that they are the best expert on their own work (Rämö 2015).

\section{Systemic Principles}

Systems built by humans such as work organizations have four systemic principles, whose violation or disregarding may cause visible and often even unacknowledged problems. The first principle is belonging, which means that everyone has a right to be seen, heard and accepted at their workplace. Ignoring and excluding a worker are strong violations of this principle (Roman 2017).

Another important perspective is the principle of giving and receiving. At the workplace this includes receiving just wages from work, a reciprocal relationship between the manager and the employee and appreciative and honest feedback received from clients and colleagues (Roman 2017).

The third principle relates to the individual's place or position in the organizational system. Theories of group dynamics have long recognized that humans will instinctually seek their place in a new community. If, for instance, a new manager joins the group either from within or outside the group, the internal hierarchy will seek a new balance, sometimes even through crisis. The highest levels of the internal, frequently invisible hierarchy are occupied by those who have been at the organization the longest, those who have the greatest skill and those with the most to lose. Hellinger (1999) speaks of the "systemic conscience", which makes the community feel experiences such as the dismissal of a single parent as more devastating than that of a colleague who can easily find a new position (Roman 2011).

The fourth principle concerns respecting reality, which requires openness at the workplace and the identification and acknowledgment of facts. Things can be discussed and problems solved only if there is enough courage to face difficult topics and address them together (Roman 2017). When workplace conflicts are seen as opportunities to develop, for example, functional processes, problem solving can focus on improving work and work assignments, rather than always finding a guilty party.

\section{Dialogue as the Foundation of Cooperation}

Social skills related to cooperative working include leadership, building trust, communication and conflict management. Cooperation means sharing professional knowledge, experiences and new ideas, which is why skills related to selfassessment and giving and receiving input are particularly important (Johnson and Johnson 2002).

According to Goleman (2009), social skills are what allow for efficient interactions between people. Their lack causes confusion and constant interpersonal 
catastrophes in communities. Mere intelligence is thus not enough to maintain functioning relationships. Social skills allow us to inspire and encourage others, present our capabilities, influence things and make others feel comfortable (Goleman 2009).

Building a dialogic interaction differs from mundane, often shallow talks, one-sided debates or fast negotiations for compromise. A dialogue is built on genuinely listening to others and recognizing and considering other perspectives while critically assessing one's own. Its goal is to change opinions and practices, to foster learning and creativity and to create something new (Alhainen et al. 2011).

According to Paulo Freire (2000), a significant feature of dialogue is the word, which has two dimensions: reflection and action. If the word, that is speech, loses its connection to practice, speech turns into mere verbalism. Genuine speech must question the world, which will allow speech to change it through action. Reflection is what makes action considered and responsible (Freire 2000).

One quality of dialogic interaction is cooperation, which can only exist between equal individuals, even though their roles and areas of responsibility may be different (Freire 2000). It is important for work communities to practice open dialogues on all levels of administration and between them. That is only possible with structures and practices that permit and support dialogue.

\section{Method}

The aim was also to find ways for employees and employers to have continuous collaboration to develop productivity and well-being at work during their ordinary working days. This article focuses on the results of two care companies that took part in the project. The research question is: What kind of effect did the project have on employees' well-being? This presentation focuses on the results of the two care companies that took part in the development project.

The data from two participating care companies were gathered through an electronic questionnaire that was filled out by the personnel at the beginning and at the end of the development project. The questionnaire consisted of more than 150 statements, most of which had a 5-point Likert scale. For this study, 62 statements measuring employee well-being at work were selected from the questionnaire and further divided into five different categories; (1) job satisfaction, (2) utilization and development of employee competence, (3) performing basic tasks, (4) functionality of the work community, and (5) functionality and safety of the work environment. The response rate was $65 \%(\mathrm{n}=65)$ at the initial measurement and $54 \%(\mathrm{n}=54)$ at the final measurement.

The data were statistically analyzed using SPSS. Statistical methods included Frequencies, Mann-Whitney and Spearman Correlation. The Mann-Whitney U test is used to measure statistical significance between initial and final measurements on each selected variable. The Spearman Correlation is used to investigate correlation between two variables, for example, mental workload and the prevalence of gossiping within the work community (Curtis and Drennan 2013). 


\section{Results}

In both measurements, the average age of the respondents $(n=65)$ was around 44 years with more than $90 \%$ of them being female. Approximately $10 \%$ were registered nurses, $70 \%$ were practical nurses and $20 \%$ were managers. $43 \%$ of the respondents had been working in their current position for less than six years, while some had more than 30 years of experience in their current position (Figure 2).

Figure 2. Respondents' Background ( $n=65$ )

- Average age: $44 \mathrm{yr} / 46 \mathrm{yr}$

- Female: $97 \% / 91 \%$

- Practical nurses $63 \% / 70 \%$

- Six or more years in current position: $57 \% / 57 \%$

- Less than one year in current position $8 \% / 17 \%$

Figure 3. Satisfaction towards Managers

Satisfaction towards managers
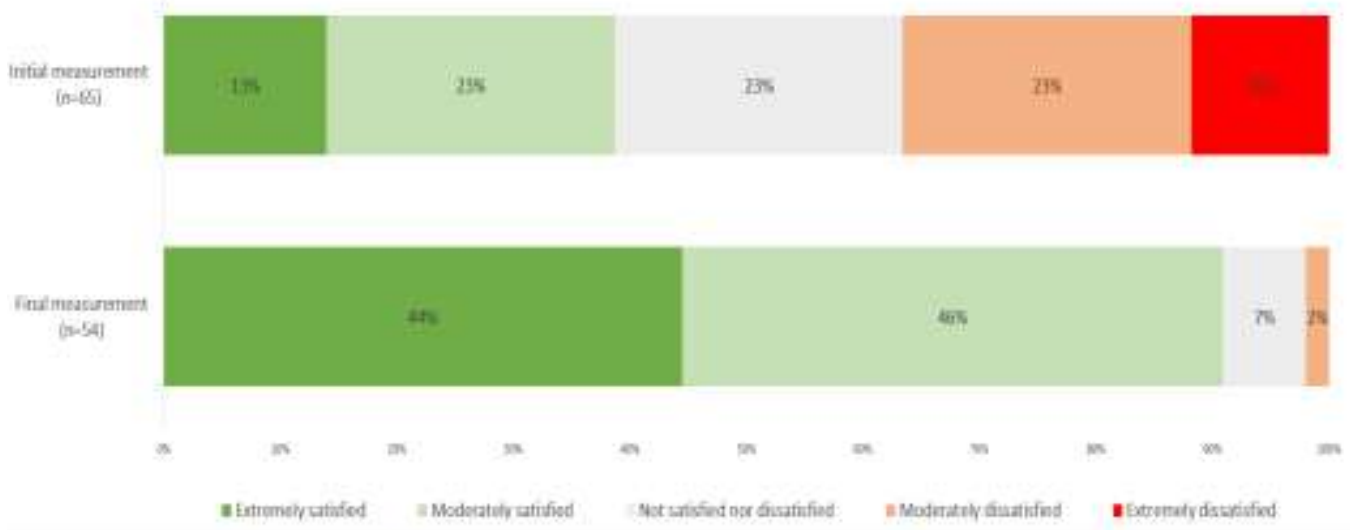

There was a statistically significant change in employees' well-being at work between the initial $(n=65)$ and final measurements $(n=54)$ in all five areas of employee well-being. In the final measurement, two statements received lower scores, 60 statements higher scores and 22 of them had a P-value less than or equal to 0.01 . The highest single improvement occurred in employees' satisfaction towards managers. In the initial measurement, $42 \%$ of the respondents were satisfied with managers, whereas in the final measurement $91 \%(\mathrm{p}<0.001)$ were satisfied with managers (Figure 3). Atmosphere in the work community was also evaluated to be more invigorating $(58 \% \rightarrow 85 \%, \mathrm{p}<0.001)$ (Figure 4). Other major changes (all $\mathrm{p}<0.001$ ) occurred in employees' possibilities to participate in decision-making $(48 \% \rightarrow 81 \%)$, employees' work motivation $(45 \% \rightarrow 80 \%)$, 
work ergonomics $(43 \% \rightarrow 78 \%)$, development of work $(43 \% \rightarrow 77 \%)$, employees' satisfaction towards management of the company $(32 \% \rightarrow 74 \%)$, and feedback given by managers $(58 \% \rightarrow 85 \%)$.

Figure 4. Atmosphere in the Work Community

\section{Working atmosphere is invigorating}
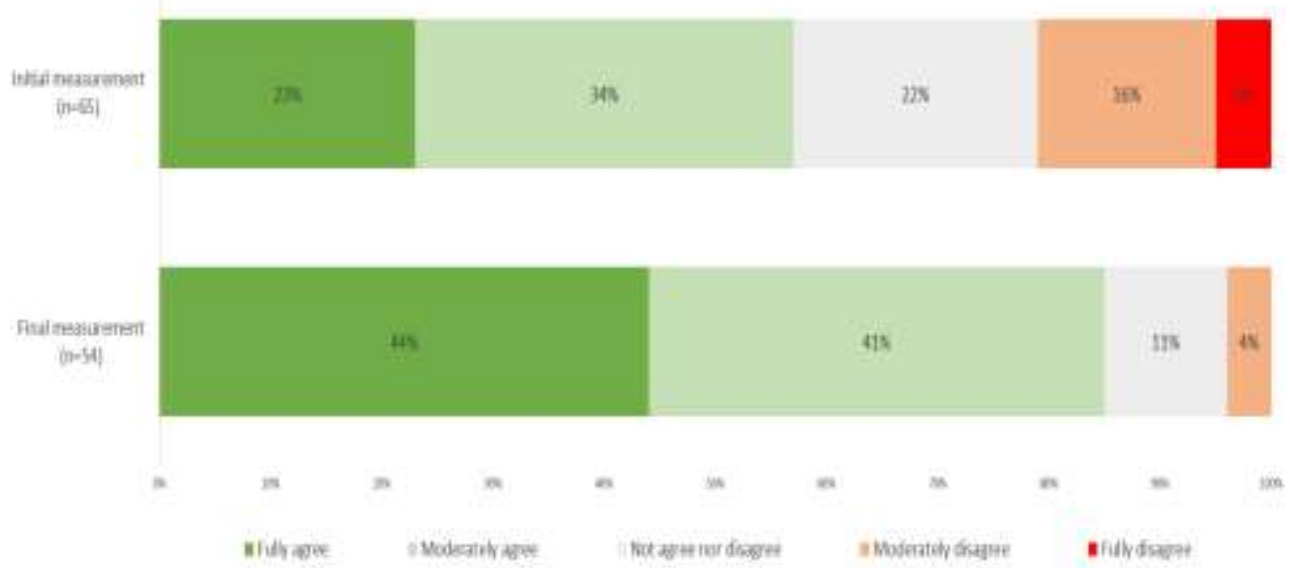

Respondents in the final measurement were asked to evaluate whether the development project had had positive, negative or no effect at all on given subjects. Respondents estimated that the development project had positively affected performing the basic tasks (53\% of respondents), personnel motivation (39\%), interpersonal relationships and atmosphere (49\%), communication (55\%), relationship between employees and employers (49\%), working conditions (44\%), initiative of personnel (44\%), possibilities for personnel to participate and influence things (42\%), bringing out the creativity of the employees $(42 \%)$, wellbeing at work (52\%), and development at the workplace (50\%) (Figure 5). Apart from one respondent who evaluated the development project to have negatively affected communication, no other respondent associated the development project with any negative effects.

Figure 5. Respondents' Views on the Effects of the Project

\begin{tabular}{|c|c|c|c|}
\hline & POSITIVELY & NO EFFECT & NEGATIVELY \\
\hline Performing the basic tasks & $53 \%$ & $47 \%$ & $0 \%$ \\
\hline Employees' work motivation & $39 \%$ & $61 \%$ & $0 \%$ \\
\hline Relationship between employees and managers & $49 \%$ & $51 \%$ & $0 \%$ \\
\hline Communication & $55 \%$ & $43 \%$ & $2 \%$ \\
\hline Well-being at work & $52 \%$ & $48 \%$ & $0 \%$ \\
\hline Bringing out the creativity of the employees & $49 \%$ & $51 \%$ & $0 \%$ \\
\hline
\end{tabular}


In the initial measurement, employees' joy through working was strongly correlated with versatility of work $(r=0.764 \mathrm{p}<0.001)$, clear distribution of work $(\mathrm{r}=0.641 \mathrm{p}<0.001)$, working according to company's values $(\mathrm{r}=0.592 \mathrm{p}<0.001)$, creating work community's rules in concert $(r=0.550 \mathrm{p}<0.001)$, satisfaction towards the company's way of rewarding and encouraging its employees $(\mathrm{r}=0.526$ $\mathrm{p}<0.001)$, possibilities to affect the content of work-tasks $(\mathrm{r}=0.524 \mathrm{p}<0.001)$, opportunities to utilize one's skills and knowledge $(\mathrm{r}=0.508 \mathrm{p}<0.001)$, fair distribution of work $(\mathrm{r}=0.501 \mathrm{p}<0.001)$, and feedback given by supervisors $(r=0.452 \mathrm{p}<0.001)$ (Figure 6). Moreover, 90\% of those respondents to whom work brought joy felt that their work was versatile and only $11 \%$ of those who considered their work to lack versatility stated that their work brought them joy. In the final measurement, more respondents $(75 \% \rightarrow 93 \%)$ felt joy through working and the correlations were generally weaker.

Figure 6. Joy through Work was correlated with Several Variables
- Versatility of work
(P<0.000 R=0.764)
- Clear distribution of work
(P<0.000 $R=0.641$ )
- Creating work-rules together
( $P<0.000 R=0.550$ )
- Opportunities to affect the contents of work
( $P<0.000 R=0.524$ )
- Opportunities to utilize one's skills
( $P<0.000 R=0.508$ )
- Fair distribution of work
( $P<0.000 R=0.501$ )
- Managers give feedback
$(P<0.000 R=0.452)$

$80 \%$ of the employees in the initial measurement and $71 \%$ in the final measurement considered their work to be mentally burdensome. Mental workload was correlated with prevalence of gossiping within the work community $(r=0.422$ $\mathrm{p}<0.001)$, lack of opportunities to affect the working pace $(\mathrm{r}=0.407 \mathrm{p}=0.001)$, inadequate communication ( $\mathrm{r}=0.389 \mathrm{p}=0.001$ ), unfair distribution of responsibilities $(\mathrm{r}=0.365 \mathrm{p}=0.003)$, not creating the work community's rules in concert $(\mathrm{r}=0.329$ $\mathrm{p}=0.008)$, and not working according to the company's values $(\mathrm{r}=0.326 \mathrm{p}=0.008)$ in the initial measurement. $85 \%$ of those respondents who considered work to be mentally light estimated that they could affect the working pace. On the other hand, $56 \%$ of respondents thought that they could affect the working pace only a little or not at all and $94 \%$ of these respondents felt that their work was mentally burdensome. In the final measurement, most variables associated with increased mental workload had gotten better, but work was still evaluated to be mentally burdensome. Correlations were also generally weaker in the final measurement.

\section{Conclusions}

Employee well-being increased during the development project. The most statistically significant changes occurred naturally in those variables which received lower scores in the initial measurement, as it is harder to improve 
something that is already working well. Only two variables received lower scores in the final measurement, but those changes were not statistically significant.

Opportunities to affect the content of work-tasks were associated with increased joy through working. The results were similar to earlier studies that show nurses' autonomy as a major source of increased job satisfaction (Hayes et al. 2015, Furtado et al. 2011, Roberts-Turner et al. 2014, Curtis and Glacken 2014, Sansoni et al. 2016). Joy through working was related to opportunities to utilize one's skills and versatility of work. Somewhat similar results appeared in Sveinsdóttir's and Blöndal's (2014) study, although they found that having nurses perform tasks which require no special knowledge and skills is correlated with nurses' intention to leave the workplace. As in the studies of Goetz et al. (2015) and Kaitelidou et al. (2012), this study also found that clear distribution of work is associated with joy though working. Overall, joy through working had strong correlations in the initial measurement, but as joy through working and associated variables received better evaluations in the final measurement, correlations became weaker. This leads to the conclusion that the joy of working can be easily ruined if work lacks, for example, versatility. However, the versatility of work alone is not a guarantee for the work to be enjoyable as there are multiple factors in play.

Like in the earlier studies (Jetha et al. 2017), poor opportunities to affect working pace increased the mental workload. Work remained mentally burdensome even though the associated variables became better in the final measurement. For example, the prevalence of gossiping was linked to increased mental workload in the initial measurement and as gossiping decreased in the final measurement the correlation vanished, but the work remained mentally burdensome. From this, it can be concluded that gossiping increases mental workload, but having a gossip-free work community is not enough for work to become mentally light. It is still unclear why work remained mentally burdensome even when the associated variables were improved. Respondents had to choose which best described their sense of mental workload from a 4-point Likert scale that lacked a neutral option. It is perhaps simply not natural for someone with a responsible job to describe their job as mentally light.

This study has some weaknesses which limit the conclusions that can be made. The response rate was lower at the final measurement, which makes the results less representative, and the sample size was quite small for the results to be generalizable. All personnel in the care companies were eligible to fill the questionnaire in the final measurement. Respondents did not have a response id and they were not asked if they had participated in the initial measurement. This means that individual respondents cannot be unified and it is impossible to know what percentage of respondents participated in both measurements.

Given the study limitations, it cannot be claimed that the positive changes during the development project were exclusively due to the project, as it is hard to identify every influencing factor. Nevertheless, it is likely that the project played a considerable role, as the changes were significant and half the respondents evaluated the project to have had a positive effect on a variety of subjects. 


\section{References}

Alhainen K, Kansanaho A, Ahtiainen O-P, Kangas M, Soini T, Soininen J (2016) Manual of Work Controls. PROTammi.

Abdelhadi N, Drach-Zahavy A (2012) Promoting Patient Care: Work Engagement as a Mediator between Ward Service Climate and Patient-centred Care. Journal of Advanced Nursing 68(6): 1276-87.

Armstrong-Stassen M, Freeman M, Cameron S, Rajacic D (2015). Nurse Managers' Role in Older Nurses' Intention to Stay. Journal of Health Organization and Management 29(1): 74-55.

Brunetto Y, Xerri M, Shriberg A, Farr-Wharton R, Shacklock K, Newman S, Dienger J (2013) The Impact of Workplace Relationships on Engagement, Well-being, Commitment and Turnover for Nurses in Australia and the USA. Journal of Advanced Nursing 69(12):2786-99.

Celma D, Martinez-Garcia E, Raya JM (2018) Socially Responsible HR Practices and their Effects on Employees' Wellbeing: Empirical Evidence from Catalonia, Spain. European Research on Management and Business Economics 24(2): 82-89.

Caricati L, La Sala R, Marletta G, Pelosi G, Ampollini M, Fabbri A, Ricchi A, Scardino M, Artioli G, Mancini T (2014) Work Climate, Work Values, and Professional Commitment as Predictors of Job Satisfaction among Nurses. Journal of Nursing Management 22(8): 984-994.

Curtis E, Drennan J (2013) Quantitative Health Research: Issues and Methods. Berkshire: Open University Press.

Curtis E, Glacken M (2014) Job Satisfaction among Public Health Nurses: A National Survey. Journal of Nursing Management 22(5): 653-663.

Freire P (2000) Pedagogy of the Oppressed. New York: Continuum.

Furtado L, Batista M, Silva F (2011) Leadership and Job Satisfaction among Azorean Hospital Nurses: An Application of the Situational Leadership Model. Journal of Nursing Management 19(8): 1047-1057.

Goetz K, Hasse P, Campbell S, Berger S, Dörfer C, Hahn K, Szecsenyi J (2015) Evaluation of Job Satisfaction and Working Atmosphere of Dental Nurses in Germany. Community Dentistry \& Oral Epidemiology 44(1): 24-31.

Goleman D (2009) Emotional Intelligence. Helsinki: Otava.

Goswami A, Nair P, Beehr T, Grossenbache M (2016) The Relationship of Leaders' Humor and Employees' Work Engagement Mediated by Positive Emotions. Leadership \& Organization Development Journal 37(8): 1083-1099.

Hayes B, Douglas C, Bonner A (2015) Work Environment, Job Satisfaction, Stress and Burnout among Haemodialysis nurses. Journal of Nursing Management 23(5): 588598.

Hellinger B, ten Hövel G (1999) Acknowledging What Is, Conversations with Bert Hellinger. Zeig. Tucker \& Co, Inc. Phoenix, Arizona.

Hsu CP, Chiang CY, Chang CW, Huang HC, Chen CC (2015) Enhancing the Commitment of Nurses to the Organisation by Means of Trust and Monetary Reward. Journal of Nursing Management 23(5): 567-76.

Jetha A, Kernan L, Kurowski A (2017) Conceptualizing the Dynamics of Workplace Stress: a Systems-based Study of Nursing Aides. BMC Health Services Research 17(1): 12-22.

Jones A (2013) Organizational Commitment in Nurses: Is it Dependent on Age or Education? Nursing Management 21(9):29-36.

Johnson D, Johnson R (2002) Learning Together. In P Sahlberg, S Sharan (eds) 
Vol. 6, No. $1 \quad$ Laaksonen et al.: Cooperative and Dialogic Development Increases...

Cooperative Learning Manual, 101-117. Helsinki: WSOY.

Kaitelidou D, Kontogianni A, Galanis P, Siskou O, Mallidou A, Pavlakis A, Kostagiolas P, Thedorou M, Liaropoulos L (2012) Conflict Management and Job Satisfaction in Paediatric Hospitals in Greece. Journal of Nursing Management 20(4): 571-578.

Kuittinen M, Kejonen M (2009) Commonality of Paradoxes: Teams and Groups of People Building Common Ground.In K Filander, M Vanhalakka-Ruoho (eds) Communion in Motion, 248-249. Jyväskylä: Gummerus.

Lorber M, Savic S (2012) Job Satisfaction of Nurses and Identifying Factors of Job Satisfaction in Slovenian Hospitals. Croatian Medical Journal 53(3): 263-270.

Manka M-L, Hakala L, Nuutinen S, Harju R (2011) Work Joy and Suck - Solutions of Wellbeing at Small Workplaces. Tampere: Tampereprint Oy.

Mähönen E (2017) Working Life Barometer. Publications of the Ministry of Economic Affairs and Employment. TEM reports 34/2017.

Nivala E (2008). Citizenship in the Global Welfare Society. Kuopio: Snellman-instituutti A-sarja 24.

Ogbonnaya C, Valizade D (2015). Participatory Workplace Activities, Employee-level Outcomes and the Mediating Role of Work Intensification. Management Research Review 38(5): 540-588.

Plester B, Hutchison A (2016) Fun Times: The Relationship between Fun and Workplace Engagement. Employee Relations 2016 38(3): 332-350.

Rämö A (2015). Simple Management - with Values. Saarijärven: Offset Oy.

Roberts-Turner R Hinds P Nelson J Pryor J Robinson N Wang J (2014) Effects of Leadership Characteristics on Pediatric Registered Nurses' Job Satisfaction. Pediatric Nursing 40(5): 236-241.

Robbins S, Judge T (2012) Organizational Behavior. Kendallville: Prentice Hall.

Roman J (2011) The Systemic Understanding and Systemic Constellation. Dialogue Institute. Retrieved from https://bit.ly/2CqyLUu. [Accessed 28 April 2017].

Roman J (2017) Window to Invisible. The Systemic Constellation and Systemic Understanding. Helsinki: BoD - Books on Demand.

Sansoni J, De Caro W, Marucci AR, Sorrentino M, Mayner L, Lancia L (2016) Nurses' Job Satisfaction: An Italian Study. Medicina Preventiva E Di Comunita 28(1): 58-6

Sawatzky J, Enns Legare C (2015) Identifying the Key Predictors for Retention in Critical Care Nurses. Journal of Advanced Nursing 71(10): 2315-2325.

Seifert M, Brockner J, Bianchi E, Moon H (2016) How Workplace Fairness Affects Employee Commitment. MIT Sloan Management Review 57(2): 15-17.

Sloan D, Buckham R, Lee Y (2017) Exploring Differentiation of Self and Organizational Commitment. Journal of Managerial Psychology 32(2):193-206.

Sveinsdóttir H, Blöndal K (2014) Surgical Nurses' Intention to Leave a Workplace in Iceland: A Questionnaire Study. Journal of Nursing Management 22(5): 543-552. 